INTERNATIONAL HIGHER EDUCATION, Number 72. Summer 2013

Pages 20-21

\title{
How Will English Higher Education Look Like in 2025?
}

JEROEN HUISMAN, HARRY DE BOER, and PAULO CHARLES PIMENTEL BÓTAS

Jeroen Huisman is professor at the University of Bath, UK. E-mail: j.huisman@bath.ac.uk. Harry de Boer is senior research associate at the University of Twente, the Netherlands. E-mail: h.f.deboer@utwente.nl. Paulo Charles Pimentel Bótas is research officer at the University of Bath, UK. E-mail: paulobotas@gmail.com. For those interested, the full scenarios can be found in Higher Education Quarterly 66 (4), 341-62.

In 2009, the Labour government asked for an independent view on the future direction of higher education funding in England. The Browne committee presented their report, Securing a Sustainable Future for Higher Education, in 2010. The new government-a coalition of the Conservative and Liberal Democrat parties-took on board many of the suggestions of the Browne committee and integrated these in its 2011 white paper- "Students at the Heart of the System." Many observers thought the proposed policies would shake up the higher education system. For example, the government proposed a set of measures that undoubtedly affect students and higher education institutions. The key elements of the white paper are that higher education institutions could set their fee levels at $£ 6,000$ up to a maximum of $£ 9,000$, which before the policy stood at $£ 3,290$. The teaching grant-allocated to higher education institutions on 
the basis of student numbers and the disciplines they were enrolled in-would disappear, making higher education institutions to a large extent dependent on the student fee income. Whereas student places were more or less fixed (as in, limited places for domestic students for each discipline/program at higher education institutions), the government proposed to make a large share-about a quarter-of the student places available on a competitive basis, allowing institutions to bid for places.

\section{IMPACT}

Observers feared that the high(er) fee levels would deter students from enrolling in higher education and that this would especially affect students from lowersocial economic backgrounds and hence threaten access to higher education. Also, some higher education institutions might lose out in the very competitive system; the largest trade union predicted that about a quarter of the higher education institutions would be threatened in their existence. It was also argued that the policies would create a new binary system, for the policies could work out well for the research-intensive universities and would be detrimental to the flourishing of the teaching-oriented institutions.

Whereas some of the expected impacts were well-argued and supported by some empirical evidence, it is obviously impossible to fully predict the outcomes of the policy reform. Bearing in mind the title of a seminal work on policy change-"Great Expectations and Mixed Performance"-the actual implementation of a policy may differ from the policy intentions. At the same time, future socioeconomic and cultural changes will continue to impact the 
system independently from the policy reform, potentially interfering with policy intentions.

\section{DELPHI STUDY}

Thus, it is relevant to discuss the potential developments, if only to engage in a debate about the future shape and size of the English higher education system and to reflect on possible outcomes in terms of likelihood and desirability. We therefore set up a Delphi study (supported by a grant from the Leadership Foundation for Higher Education). In the Delphi study, higher education experts were asked to reflect on statements on the potential developments and situations in 2025 (e.g., "In English higher education in 2025, private providers cater for $15 \%$ of students."). In our study, in total 44 experts commented individually on the likelihood and desirability of certain developments toward 2025 (21 statements were offered). In the second round, 70 percent of the experts reflected

on the full set of first-round arguments, claims, and assertions. Several rounds of reflections can be used for a Delphi study, (e.g., to reach consensus). We thought the data from the two rounds were sufficiently rich and used arguments from the full set of data to build two scenarios for English higher education.

\section{SCENARIO 1: RETURN OF THE BINARY DIVIDE BY 2025}

The first scenario departs from the assumption that the market mechanisms introduced in the past two decades or so, will continue to coordinate the system. This will imply a somewhat smaller system in 2025, due to mergers and some institutions not having survived the financial crises. The differences between the 
traditional universities and former polytechnics increased, and a new binary line emerged. The system in 2025 consists of about 25 research-intensive universities and 70 other higher education institutions. The sector of research-intensive institutions is rather homogeneous; and institutions still figure largely in the global rankings, if only for the fact that international competitors also suffered from the global crises. The nonresearch sector is much more diverse, but has in common a focus on undergraduate programs, although there are some pockets of research excellence. Private (for-profit) institutions have been able to enter the market and there will be-in 2025-a substantial number of smaller and medium-size private universities.

\section{SCENARIO 2: RETURN OF THE Visible HAND}

This scenario argues that increasing criticism on the failure of market mechanisms, to live up to the promises, has led to a situation that the government was forced to step in directly. More investments, combined with strong governmental regulation, have led to a three-tier system in 2025: six research-intensive universities (the Super Six have been able to pursue excellence strategies and belong to the small group of world-class universities) that set relatively high fees; about 40 comprehensive universities with broad missions (the Grand Universities); and five private universities (that have a hard time as students decide to go public). The system is much smaller due to enforced regional mergers between comprehensive institutions. These institutions thrive,

partly because of good networks and cooperation between them, combined with strong institutional leadership and management. 


\section{Conclusion}

Both scenarios imply a rather drastic change to the English higher education system, a change comparable to the abolishment of the binary system in 1992: the number of institutions will change, as well as their profiles (research or teaching focused, not-for-profit versus private institutions). There will be serious implications for access, funding, and quality assurance. The scenarios contain more details, also on teaching and learning and the student body. Of course, in 2025 our predictions will be proven wrong, but that is not the point. We hope that in the coming years the scenarios will stimulate a debate on the future worlds that academics, higher education managers, policymakers, and students would like to live in. 